\title{
Theoretical considerations on germline mosaicism in Duchenne muscular dystrophy
}

\author{
Tiemo Grimm, Bertram Müller, Clemens R Müller, Michael Janka
}

\begin{abstract}
A newly formulated mutation selection equilibrium for lethal X linked recessive traits such as Duchenne muscular dystrophy is presented, which allows for both male and female germline mosaicism. Estimates of the additional parameters used are given, thus allowing the incorporation of germline mosaicism into the calculation of genetic risks.
\end{abstract}

Germline mosaicism, that is, the occurrence of a mutation of a certain gene during the development of germ cells, has been observed or suggested in a variety of diseases. These include ectrodactyly, ${ }^{12}$ aniridia ${ }^{3}$ achondroplasia, ${ }^{4-8}$ haemoglobin Köln, ${ }^{9}$ Apert's syndrome, ${ }^{10}$ Rett's syndrome, ${ }^{11} 12$ tuberous sclerosis, ${ }^{1314}$ Duchenne muscular dystrophy, ${ }^{15-22}$ ornithine transcarbamylase deficiency, ${ }^{23}$ pseudochondroplasia, ${ }^{24}$ haemophilia $A, 25$ osteogenesis imperfecta type II, ${ }^{26}$ Crouzon's syndrome, ${ }^{27}$ and chromosome abnormalities. ${ }^{28}$

The aim of this paper is to investigate how the existence of germline mosaicism may be incorporated into the estimation of risks in DMD. DMD is a good model for the investigation of germline mosaicism owing to the high rate of new mutations, the availability of direct gene and carrier tests in a high proportion of families, and the high incidence of the disease.

\section{Methods}

In order to include germline mosaicism in risk estimations in DMD, it is necessary to redefine the mutation selection equilibrium formulated by Haldane $^{29}$ in 1935 (table 1).

After the model of Haldane, the mutation has to occur in the first or second meiotic division. A

Institut für Humangenetik, Universität Würzburg, Koellikerstrasse 2, D-8700 Würzburg, Federal Republic of Germany.

T Grimm, B Müller, C R Müller, M Janka

Correspondence to Professor Grimm.

Received for publication 21 March 1990

Accepted for publication 5 April 1990.
Table 1 Mutation selection equilibrium ( $\mu=$ mutation rate).

\begin{tabular}{lcc}
\hline & \multicolumn{2}{c}{ Frequency of } \\
\cline { 2 - 3 } & Heterozygotes & Affected males \\
\hline Parent generation & $4 \mu$ & $3 \mu$ \\
$\begin{array}{l}\text { Mutations inherited } \\
\text { Mutations occurring } \\
\text { de novo }\end{array}$ & $2 \mu$ & $2 \mu$ \\
$\begin{array}{l}\text { Generation of } \\
\text { children }\end{array}$ & $2 \mu$ & $3 \mu$ \\
\hline
\end{tabular}

mutation occurring after the primordial germ cell will lead to more than one oocyte or sperm carrying the mutation. This will be called germline mosaicism in the following. Mutation in the meiotic divisions may be considered an extreme case of germline mosaicism with only one oocyte or sperm instead of many carrying the mutation.

Mutations occurring after fertilisation and before differentiation of the primordial germ cell will present as somatic mosaics. Only those cells descending from the cell which first carried the mutation will be affected. If the primordial germ cell is among those descendent cells, about $50 \%$ of oocytes and spermatocytes will carry the mutation.

Therefore in order to define a new mutation selection equilibrium, two additional parameters have to be included. They are:

g-proportion of mutations leading to germline mosaicism.

f-mean proportion of half of oocytes or spermatocytes with an $\mathrm{X}$ chromosome in the population carrying a mutation resulting from germline mosaicism.

Equal transmission probabilities and equal mutation rates in males and females are assumed. ${ }^{30}$ There was no evidence for different mutation rates in males and females in our own data (211 DMD families) (Grimm $e t a l$, in preparation). Mutation rate as used in this paper is defined as the rate of mutations per gene (in this case the gene coding for dystrophin) per generation. ${ }^{31}$ The reformulated mutation selection equilibrium is shown in table 2 . In this model, which has been formulated under the above assumptions, a carrier has inherited her DMD allele from her 
Table 2 Mutation selection equilibrium under the assumption of germline mosaicism ( $\mu=$ mutation rate, $g=$ proportion of mutations leading to germinal mosaicism, $f=$ mean proportion of half of oocytes or spermatocytes with an $X$ chromosome in the population carrying a mutation owing to germinal mosaicism).

\begin{tabular}{|c|c|c|c|c|}
\hline & \multicolumn{4}{|c|}{ Frequency of } \\
\hline & Heterozygotes & $\begin{array}{l}\text { Germline mosaicism } \\
\text { in females }\end{array}$ & $\begin{array}{l}\text { Germline mosaicism } \\
\text { in males }\end{array}$ & $\begin{array}{l}\text { Affected } \\
\text { males }\end{array}$ \\
\hline Parent generation & $4(1-g+g f) \mu$ & & $g \mu$ & $3(1-g+g f) \mu$ \\
\hline Mutations inherited & $2(1-\mathrm{g}+\mathrm{gf}) \mu+\mathrm{fg} \mu+$ & & & $(1-g+g f) \mu+f g$ \\
\hline Mutations occurring de novo & $2(1-g) \mu$ & $2 \mathrm{~g} \mu$ & $g \mu$ & $(1-g) \mu$ \\
\hline Generation of children & $4(1-g+g f) \mu$ & $2 \mathrm{~g} \mu$ & g $\mu$ & $3(1-g+g f) \mu$ \\
\hline
\end{tabular}

mother, who is a carrier herself $[2(1-\mathrm{g}+\mathrm{gf}) \mu]$ or is a germline mosaic [gf $\mu$ ], or from a mosaic father [gf $\mu$ ]. As can be seen, the probabilities for a carrier woman to inherit her DMD allele from either a germline mosaic father or mother are equal [gfu]. Finally, she can also be a new mutation $[2(1-\mathrm{g}) \mu]$. A male can be affected because his mother is a carrier $[2(1-\mathrm{g}+\mathrm{gf}) \mu]$, a germline mosaic $[\mathrm{gf} \mu]$, or because he is a new mutation $[(1-\mathrm{g}) \mu]$.

Under this model an average of $2 / 3$ of mothers of DMD patients are carriers, a proportion of $\mathrm{gf} /[3(1-\mathrm{g}+\mathrm{gf})]$ are germline mosaics, and in $(1-g) /[3(1-g+g f)]$ the patient represents a new mutation.

\section{Results}

In order to include the mutation selection equilibrium formulated in table 2 in risk calculations, it is helpful to estimate the parameters $g$ and $f$. Both $g$ and $f$ have to be within the interval $[0 ; 1]$. Although attempts have been made to estimate the proportion of germ cells carrying a mutation based on sibship structure, ${ }^{32}$ we will restrict ourselves to estimating $f$, which is a population value. This approach is independent of sibship size and greatly facilitates computations.

Germline mosaicism can be shown directly only in families with at least two gene carriers in one sibship (affected males or heterozygous females) with a recognisable structural anomaly in the DMD gene. In the case of germline mosaicism, this anomaly will be demonstrable in neither the mother nor the father of these gene carriers. For the estimation of $g$ and $f$ only families with two affected sons with no previous family history will be considered.

A family of this type may be found owing to:

(1) mother being a carrier

owing to a mutation

having two affected sons
(2) mother being a carrier owing to germline mosaicism in her father having two affected sons

$$
=\mathrm{gf} \mu
$$$$
=1 / 4
$$

(3) mother being a carrier owing to germline mosaicism in her mother having two affected sons

$$
\begin{aligned}
& =g f \mu \\
& =1 / 4
\end{aligned}
$$

(4) both mother and grandmother being carriers having two affected sons having no family history

(5) germline mosaicism in the mother having two affected sons

Thus the probability (p) of germline mosaicism in this subgroup of mothers is: $\mathrm{p}=\frac{2 / 4 \mathrm{g \mu f}^{2}}{1 / 2(1-\mathrm{g}) \mu+1 / 4 \mathrm{gf} \mu+1 / 4 \mathrm{gf} \mu+1 / 2 \times(1-g+g f) \mu+2 / 4 g \mu \mathrm{f}^{2}}$
or

$$
\mathrm{p}=\frac{\mathrm{gf}^{2}}{(1+\mathrm{x})(1-\mathrm{g}+\mathrm{gf})+\mathrm{gf}^{2}}
$$

Solving (2) for $\mathrm{g}$ yields (3):

$$
g=\frac{1}{1-f+f^{2}(1-p) / p(1+x)}
$$

\section{Darras et $a l^{18}$ estimated $\mathrm{p}$ to be about $0 \cdot 1$.}

Bakker $e t a l^{20}$ reported an increased recurrence risk for 'new' Duchenne muscular dystrophy mutations. They pointed out that in the case of an apparent 'new $N$ mutation' in DMD there was a recurrence risk of at least 7\%. This figure was then given as the risk to be used in counselling mothers and sisters of apparent new mutations.

After the new mutation selection equilibrium (table 2), using a Bayesian approach the recurrence risk (B) 0 for the mother of an apparent new mutation may be expressed as 
Table 3 Risk calculation under the condition of germline mosaicism.

\begin{tabular}{|c|c|c|c|c|c|c|}
\hline \multirow{3}{*}{$\begin{array}{l}\text { Mother } \\
\text { Affected son } \\
\text { Fetus }\end{array}$} & \multicolumn{2}{|c|}{ Carrier } & \multicolumn{2}{|c|}{ Germline mosiacism } & \multicolumn{2}{|c|}{ Non-carrier } \\
\hline & \multicolumn{2}{|c|}{$4(1-g+g f) \mu$} & \multicolumn{2}{|c|}{$2 \underset{1 / 2 f}{g \mu}$} & \multicolumn{2}{|c|}{$\stackrel{1}{(1-g) \mu}$} \\
\hline & $\begin{array}{c}\text { Affected } \\
1 / 2 \\
(1-g+g f) \mu\end{array}$ & $\begin{array}{l}\text { Unaffected } \\
1 / 2 \\
(1-g+g f) \mu\end{array}$ & $\begin{array}{c}\text { Affected } \\
1 / 2 \mathrm{f} \\
1 / 2 \mathrm{gf}^{2} \mu\end{array}$ & $\begin{array}{c}\text { Unaffected } \\
1 / 2+1 / 2(1-\mathrm{f}) \\
\mathrm{gf} \mu-1 / 2 \mathrm{gf}^{2} \mu\end{array}$ & $\begin{array}{l}\text { Affected } \\
(1-g) \mu \\
(1-g)^{2} \mu^{2}\end{array}$ & $\begin{array}{c}\text { Unaffected } \\
1 \\
(1-g(\mu)\end{array}$ \\
\hline Fetus (affecte & $\frac{+g f)+1 / 2 g f^{2}}{1-g+g f}$ & Mother (ger & losaic $) \approx$ & & & \\
\hline
\end{tabular}

$B=\frac{1 / 2 g^{2}}{1-g+g f}$

and solving (4) for $g$ yields (5):

$$
g=\frac{B}{B+1 / 2 f^{2}-B f}
$$

With the help of (3) and (5) $\mathrm{x}$ can be estimated:

$x=\frac{2 B-2 B p-p}{p}$

If $B=0 \cdot 07$ and $p=0 \cdot 1$ then $x=0 \cdot 26$. In our own DMD families we estimated $x$ to be about $0 \cdot 25$.

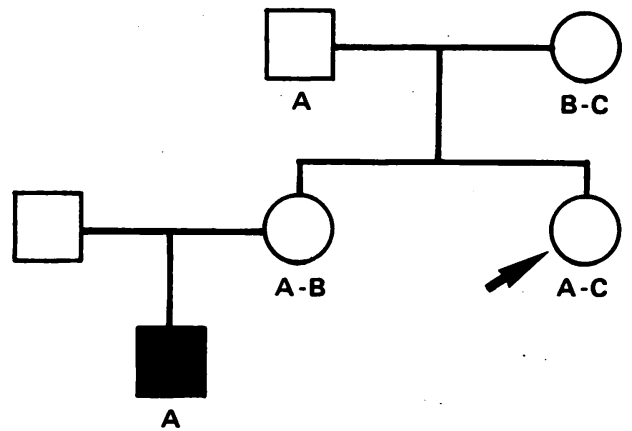

DMD pedigree. The aunt of the affected boy is the consultand.

DNA haplotyping shows that the affected boy has a grandpaternal haplotype ( $A=$ grandpaternal, $B$ and C= grandmaternal haplotype).
Barbujani $e t a l^{34}$ estimated the proportion (D) of mothers of DMD patients being a germline mosaic to be at least $10 \%$. This estimate was derived from segregation analysis in 1885 DMD families.

After the new mutation selection equilibrium, D will be:

$$
\mathrm{D}=\frac{\mathrm{g} \mathrm{f}}{3(1-\mathrm{g}+\mathrm{gf})}=\frac{2 \mathrm{~B}}{3 \mathrm{f}}
$$

solving (7) for $\mathrm{g}$ yields (8):

$$
g=\frac{1}{1-f+f /(3 D)}
$$

from (5) and (8):

$$
\frac{B}{B+1 / 2 f^{2}-B f}=\frac{1}{1-f+f /(3 D)}
$$

(9) may be solved for $\mathrm{f}$ :

$$
\mathrm{f}=\frac{2 \mathrm{~B}}{3 \mathrm{D}}
$$

If $B=0.07$ and $D \geqslant 0.1$ then $f \leqslant 0.47$ and $g \geqslant 0.48$. The minimum for $\mathrm{f}$ will be about $0 \cdot 14$, because then $g=1$. With B fixed at 0.07 it follows from the constraints on $f$ and $g$ that $D$ has to be equal or more than 0.05 (at $f=1.00$ and $g=0.14$ ) and equal or less

\begin{tabular}{|c|c|c|c|c|c|}
\hline \multirow{3}{*}{$\begin{array}{l}\text { Grandfather } \\
\text { Mother } \\
\text { Son affected } \\
\text { Mutation on the } \\
\text { grandpaternal haplotype }\end{array}$} & \multicolumn{2}{|c|}{ Germline mosaicism } & \multicolumn{3}{|c|}{ Normal } \\
\hline & & & $\begin{array}{c}\text { Carrier } \\
\text { (new mutation) }\end{array}$ & $\begin{array}{c}1 \\
\text { Germline } \\
\text { mosaicism }\end{array}$ & Not carrier \\
\hline & & & $\begin{array}{c}2(1-g) \mu \\
1 / 2\end{array}$ & $\begin{array}{l}2 \mathrm{~g} \mu \\
1 / 2 \mathrm{f}\end{array}$ & $\stackrel{1}{(1-g)} \mu$ \\
\hline $\begin{array}{l}\text { grandpaternal haplotype } \\
\text { Aunt }\end{array}$ & $\begin{array}{l}\text { Carrier } \\
\mathrm{f} \\
1 / 2 \mathrm{gf}^{2} \mu\end{array}$ & $\begin{array}{l}\text { Not carrier } \\
1-f \\
1 / 2 g f(1-f) \mu\end{array}$ & $\begin{array}{c}1 / 2 \\
\text { Not carrier } \\
1 \\
1 / 2(1-\mathrm{g}) \mu\end{array}$ & $\begin{array}{c}1 / 2 \\
\text { Not carrier } \\
1 \\
1 / 2 \mathrm{gf} \mu\end{array}$ & $\begin{array}{c}1 / 2 \\
\text { Not carrier } \\
1 \\
1 / 2(1-g) \mu\end{array}$ \\
\hline Aunt (carrier) $=\frac{\mathrm{gf}^{2}}{2(\mathrm{gf}+1-\mathrm{g})}$ & \multicolumn{5}{|c|}{ Grandfather (germline mosaic) $=\frac{\text { gf }}{2}$} \\
\hline
\end{tabular}
than 0.33 (at $\mathrm{f}=0.14$ and $\mathrm{g}=1.00$ ).

The proportion of mothers being a germline mosaic among all female gene carriers $(M)$ is:

Table 4 Risk calculation under the condition of germline mosaicism for the consultand in the figure. 


$$
M=\frac{g}{g+2(1-g+g f)}
$$

Under the constraints put on $\mathrm{f}$ and $\mathrm{g}$ above:

$0 \cdot 24 \leqslant M \leqslant 0 \cdot 78$.

\section{EXAMPLE CALCULATIONS}

The following calculations will show an application of the new mutation selection equilibrium to risk calculations in DMD.

A small family with only one child, a boy affected with DMD, is assumed. A negative history for DMD is also assumed. In the absence of CK and DNA information a risk of $1 / 3$ or roughly $33.3 \%$ would be given for a male fetus to be affected.

Allowing for germline mosaicism, the Bayesian approach shown in table 3 applies and the risk of the fetus being affected $\left(R_{F}\right)$ may, discounting a second, independent, new mutation, be given as:

$R_{F}=\frac{1-g+g f+1 / 2 g^{2}}{3(1-g+g f)}=1 / 3+B / 3$

Under the condition that $\mathrm{B}=0.07$, the resulting risk figure is 0.36 instead of 0.33 without germline mosaicism.

In a second step, let the index patient have a grandpaternal haplotype in the dystrophin gene region; the possibility of undetectable crossover be discounted, and a detectable deletion not be present. The aunt of the affected boy is requesting her carrier risk (figure).

In the above situation the aunt is at risk only in the case of germline mosaicism in the grandfather or in the case of a second, independent, new mutation, the latter being discounted because of its low probability. The Bayesian approach for this situation is shown in table 4. The risk for the aunt $\left(R_{H}\right)$ is:

$R_{H}=\frac{g ~ f^{2}}{2(1-g+g f)}=B$

The resulting carrier risk $\left(R_{H}\right)$ is 0.07 (if $B=0.07$ ). The probability that the grandfather is a germline mosaic $(G)$ is:

$$
G=\frac{g f}{2(1-g+g f)}=\frac{B}{f}
$$

$G$ is between $0.07(B=0.07, f=1.00)$ and $0.5(B=0.07$, $f=0 \cdot 14)$. At $D=0 \cdot 1 \mathrm{G}$ is $0 \cdot 15$.

\section{Discussion}

Problems in risk estimation similar to those posed by germline mosaicism are caused by half chromatid mutations. ${ }^{35} 36$ However, these are not discussed in this paper.

Under the germline mosaicism hypothesis, risk figures are dependent on $g$ and $f$. Hartt ${ }^{32}$ and Murphy et $a l^{33}$ followed approaches different from ours by developing methods to estimate the proportion of mutated germ cells for an individual subject. Our approach aims at the estimation of the parameters $g$ and $f$, which we defined above as describing a population, not an individual subject. This has the great advantage of resulting in considerably easier algebra. By redefining the mutation selection equilibrium it may readily be used in Bayesian risk calculations and incorporating it into existing and widely used computer programs such as LINKAGE ${ }^{37}$ seems desirable.

The published empirical data ${ }^{182034}$ and our theoretical data show that the influence of germline mosaicism on risk figures in DMD is substantial.

As it is important to have reliable data on the frequency of germline mosaicism it is vital to define first what is meant by the frequency of germline mosaicism. Two definitions appear of practical value. The first defines the frequency of germline mosaicism as the proportion of germline mosaics among all female gene carriers, which is equivalent to formula (11). The frequency, then, would be $M$. As stated above, $M$ should be between $0.24(B=0.07, D=0.10)$ and $0.78(B=0.07, D=0.33)$. A second definition of the frequency of germline mosaicism could be the proportion of patients whose mothers are germline mosaics, which is the one used by Barbujani et al..$^{34}$ This corresponds to the D in formula (7). We could show that $\mathrm{D}$ has to be equal to or more than 0.05 (at $f=1.00$ and $g=0.14$ ) and equal to or less than 0.33 (at $\mathrm{f}=0.14$ and $\mathrm{g}=1 \cdot 00$ ).

It follows from this model that the mutation rate for the DMD locus should be notably higher than previously indirectly estimated. Disregarding germline mosaicism, the mutation rate is one third of the incidence $(\mathrm{I}) .{ }^{29}$ Incorporating germline mosaicism the mutation rate is:

$$
\begin{aligned}
& \mu=\frac{I}{3(1-g+g \text { f })} \\
& \text { If } g=0 \cdot 48, f=0 \cdot 47 \text {, and } I \approx 3 \times 10^{-4} \text {, then } \mu \approx 1 \cdot 3 \times 10^{-4} \text {. }
\end{aligned}
$$

As a practical consequence of our considerations it would appear imperative to consider prenatal diagnosis in the mother of a seemingly 'new mutation', as she could very well be a germline mosaic for DMD.

Further investigation is needed to strengthen the estimates of $g$ and $f$.

1 MacKenzie HJ, Penrose LS. Two pedigrees of ectrodactyly. Ann Eugen 1951;16:88.

2 David TJ. Dominant ectrodactyly and possible germinal mosaicism. F Med Genet 1972;9:316-20.

3 Reed TE, Falls HF. A pedigree of aniridia with a discussion of germinal mosaicism in man. Am $\mathcal{f}$ Hum Genet 1955;7:28-38.

4 Bowen P. Achondroplasia in sisters with normal parents. Birth Defects 1974;10:31-6.

5 Fryns JP, Kleczkowska A, Verresen $\mathbf{H}$, van den Berghe $\mathbf{H}$. 
Germinal mosaicism in achondroplasia: a family with 3 affected siblings of normal parents. Clin Genet 1983;24:156-8.

6 Opitz JM. Editorial comment. 'Unstable premutation' in achondroplasia: penetrance vs phenotrance. Am f Med Genet 1984;19: $251-4$.

7 Reiser CA, Pauli RM, Hall JG. Achondroplasia: unexpected familial recurrence. Am $\mathcal{F}$ Med Genet 1984;19:245-50.

8 Philip N, Auger M, Mattei JF, Giraud F. Achondroplasia in sibs of normal parents. F Med Genet 1988;25:857-9.

9 Bradley TB, Wohl RC, Petz LD, Perkins HA, Reynolds RD. Possible gonadal mosaicism in a family with hemoglobin Köln Fohns Hopkins Med F 1980;146:236-40.

10 Allanson J. Germinal mosaicism in Apert syndrome. Clin Genet 1986;29:429-33.

11 Romeo G, Archidiacono N, Ferlini A, Rocchi M. Rett syndrome: lack of association with fragile site Xp22 and strategy for genetic mapping of X-linked new mutations. Am 7 Med Genet (Suppl) 1986;1:355-9.

12 Comings DE. The genetics of Rett syndrome: the consequences of a disorder where every case is a new mutation. $A m \mathcal{F} M e d$ Genet (Suppl) 1986;1:383-8.

13 Connor JM, Stephenson JBP, Hadley MDM. Non-penetrance in tuberous sclerosis. Lancet 1986;ii: 1275 .

14 Hall JG, Byers PH. Genetics of tuberous sclerosis. Lancet $1987 ; \mathbf{i}: 751$.

15 Bakker E, Van Broeckhoven C, Bonten EJ, et al. Germline mosaicism and Duchenne muscular dystrophy mutations. Nature 1987;329:554-6.

16 Bech-Hansen NT, Starozik DM, Dimmik L, Hoar DI, Meschino W. Interstitial deletion and male-gonadal mosaicism as the basis for Duchenne muscular dystrophy. Am f Hum Genet 1987;41: 93A.

17 Darras BT, Francke U. Male germline mosaicism for DMD deletion mutation: implications for genetic counseling. $A m \mathcal{F}$ Hum Genet 1987;41:95A.

18 Darras BT, Blattner P, Harper JF, Spiro AJ, Alter S, Francke U. Intragenic deletions in 21 Duchenne muscular dystrophy (DMD)/Becker muscular dystrophy (BMD) families studied with the dystrophin cDNA: location of breakpoints on HindIII and BglII exon-containing fragment maps, meiotic and mitotic origin of the mutations. Am f Hum Genet 1988;43:620-9.

19 Wood S, McGillivray BC. Germinal mosaicism in Duchenne muscular dystrophy. Hum Genet 1988;78:282-4.

20 Bakker E, Veenema H, Den Dunnen JT, et al. Germinal mosaicism increases the recurrence risk for 'new' Duchenne muscular dystrophy mutations. $\mathcal{F}$ Med Genet 1989;26:553-9.

21 Francke U, Darras BT, Hersh JH, Berg BO, Miller RG. Brother/sister pairs affected with early-onset, progressive muscular dystrophy: molecular studies reveal etiologic heterogeneity. Am f Hum Genet 1989;45:63-72.

22 Speer A, Spiegler AW, Hanke R, et al. Possibilities and limitation of prenatal diagnosis and carrier determination for Duchenne and Becker muscular dystrophy using cDNA probes. $\mathcal{f}$ Med Genet 1989;26:1-5.

23 Brusilow S, Valle D. Allopurinol (AP) induced orotidinuria (ODNU): a test of heterozygosity from ornithine transcarbamylase (OTC) deficiency. Pediatr Res 1987;21:289A

24 Hall JG, Dorst JP, Rotta J, McKusick VA. Gonadal mosaicism in pseudoachondroplasia. Am $\mathcal{F}$ Med Genet 1987;28:143-51.

25 Youssoufian H, Antonarakis SE, Kasper CK, Phillips DG, Kazazian $\mathrm{HH}$. The spectrum and origin of mutations in hemophilia A. Am f Hum Genet 1987;41:249A.

26 Byers PH, Tsipouras P, Bonadio JF, Starmann BJ, Schwartz RC. Perinatal lethal osteogenesis imperfecta (OI type II): a biochemically heterogeneous disorder usually due to new mutations in the genes for type I collagen. Am $\mathcal{F}$ Hum Genet 1988;42: $237-48$.

27 Rollnick BR. Germinal mosaicism in Crouzon syndrome. Clin Genet 1988;33:145-50

28 Masada CT, Olney AH, Fordyce R, Sanger WS. Partial deletion of $14 \mathrm{q}$ and partial duplication of $14 \mathrm{q}$ in sibs: testicular mosaicism for $\mathrm{t}(14 \mathrm{q} ; 14 \mathrm{q})$ as a common mechanism. Am f Med Genet 1989;34:528-34.

29 Haldane JBS. The rate of spontaneous mutation of a human gene. 7 Genet 1935;31:317-26.

30 Edwards JH. Familiarity, recessivity and germline mosaicism. Ann Hum Genet 1989;53:33-47.

31 Cavalli-Sforza LL, Bodmer WF. The genetics of human populations. San Francisco: Freeman, 1971.

32 Hartl DL. Recurrence risks for germinal mosaics. Am f Hum Genet 1971;23:124-34.

33 Murphy EA, Cramer DW, Kryscio RJ, Brown CC, Pierce ER. Gonadal mosaicism and genetic counselling for $\mathrm{X}$-linked recessive lethals. Am f Hum Genet 1974;26:207-22.

34 Barbujani G, Russo A, Danieli GA, Spiegler AWJ, Borkowska J, Hausmanova Petrusevic I. Segregation analysis on 1885 DMD families. Significant departure from the expected proportion of sporadic cases. Hum Genet 1990;84:522-6.

35 Gartler SM, Francke U. Half chromatid mutations: transmission in humans? Am F Hum Genet 1975;27:218-23.

36 Grimm $T$. The influence of half-chromatid mutations on the ratio of new mutations in lethal $\mathrm{X}$-linked recessive disorders. Am $\mathrm{f}$ Hum Genet 1982;34:142-5.

37 Lathrop GM, Lalouel JM. Easy calculation of lod scores and genetic risks on small computers. Am f Hum Genet 1984;36: $460-5$. 